\title{
Exploring a Waste Dump Site Failure - Possible Causes and Prevention Measures
}

\author{
D.H. Zou \\ Dalhousie University, Halifax, Canada
}

\begin{abstract}
Construction wastes are normally stored in areas away from urban cities. If the pile of the dumped wastes becomes too high, there will be a stability concern in addition to environmental issues. As an example to address this concern and to avoid possible failure of a waste site, this paper explores the recent slide failure of a construction waste dump site near a city in southern China. Information is gathered from online sources, news reports and Google earth images. Based on the available information, the prefailure profile of the waste site is re-constructed. The stability of the waste pile is analyzed with numerical modelling based on simplified models of various scenarios. The intention is to explore the most influential factors which may cause failure on a dump site and to provide suggestions for prevention of failure in similar conditions. The analysis identified slope angle and height of a waste pile and water condition onsite as the most influential factors. General prevention measures are recommended.
\end{abstract}

Keywords: slide failure, quarry, construction dump site, satellite imagery analysis, numerical modelling

\section{The Slide Failure in December 2015}

A few days before Christmas in December 2015, a slide failure occurred on a construction waste dump site near a city in southern China (called WDS slide hereunder for simplicity). The slide destroyed and buried industrial and residential buildings in a nearby industrial park. Casualties and missing people were reported (Sina News 2015, Wangyi News 2015, Wikipedia 2015).

According to a geological report by the Ministry of Land and Resources of China (MLR 2015), waste materials generated from construction work elsewhere had been dumped on the site of a former quarry. It was the pile of construction wastes that collapsed and the natural hill did not.

The event of failure occurred quickly and travelled a distance of over $750 \mathrm{~m}$ to an industrial park down the hill, as illustrated in Fig. 1. It buried everything on its way and destroyed a few buildings in the industrial park (Xinhua News
2015, Watkings 2015). Rescue activities lasted for several days to search for survivors and involved use of many excavators.

There have been numerous reports on this event by various media after it occurred. Those reports were mostly about the event itself and not much on the technical aspects of the slide. This paper intends to fill this gap by looking at the event from a scientific point of view. Efforts have been made to collect as much and as accurate data as possible about the slide site before the failure. Because of very limited accesses to the site and engineering documents, information is mostly collected from online sources and satellite images. As a result, caution must be exercised in use of the information and the results generated.

Activities which led to the event and the site conditions are also reviewed. A conceptual model of the slide is created and the stability of the dump site is evaluated with consideration of factors which were likely to exist before the slide.

\footnotetext{
* Corresponding Author: D.H. Zou, Email: steve.zou@dal.ca, Tel: (902) 494-3977
} 


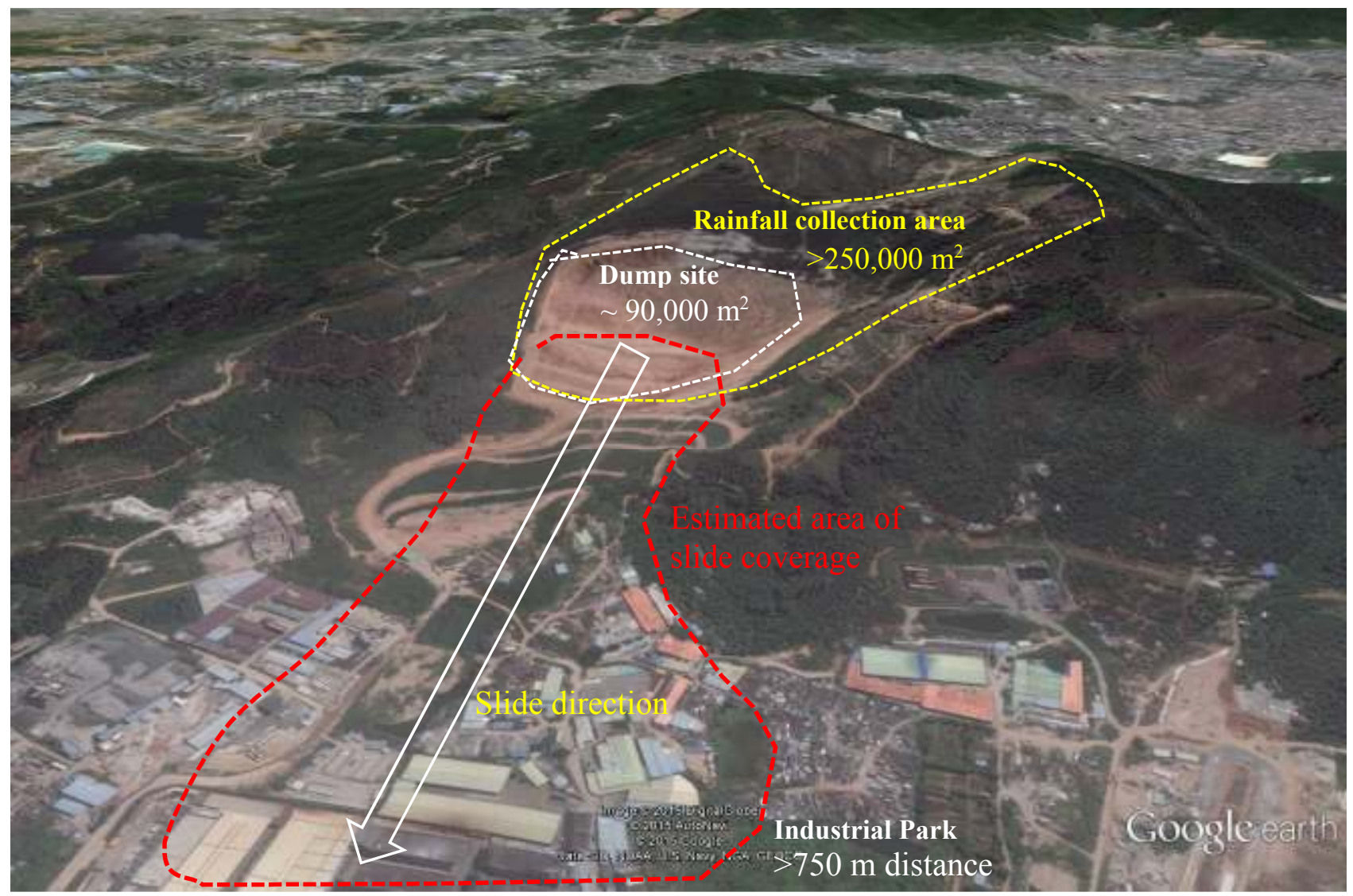

Fig. 1 Bird view of the WDS slide site before the failure (Google earth image facing South, Oct. 2015).

\section{On Site Activities prior to the Slide}

Based on various sources of reports, there was once a quarry on the site. The quarry was closed several years ago after its operation. Later the quarry pit became a pond due to accumulation of rainfall water (Fig. 2). It was reported that dumping of construction wastes on the site from other places started about two years before the slide.

In general, use of an abandoned quarry as a dump site of construction materials seems to be a natural and logic choice. If it is planned properly, this type of practice would serve dual purposes: storage of construction wastes and reclamation of the abandoned quarry site. However on a particular site, engineering assessment on the ground/dump stability and environment should be conducted by professional engineers and adequate measures should be taken to ensure proper disposal of the waste materials and to protect the area.

Dumping on the WDS site was reported to be a continuous process, day and night, over a period of more than two years prior to the event. Construction materials built up very quickly on the site. Based on Google earth images, the quarry site seemed to have been filed up to close to the highwall crest of the quarry prior to the event (Figs. 1, 3 and 4).

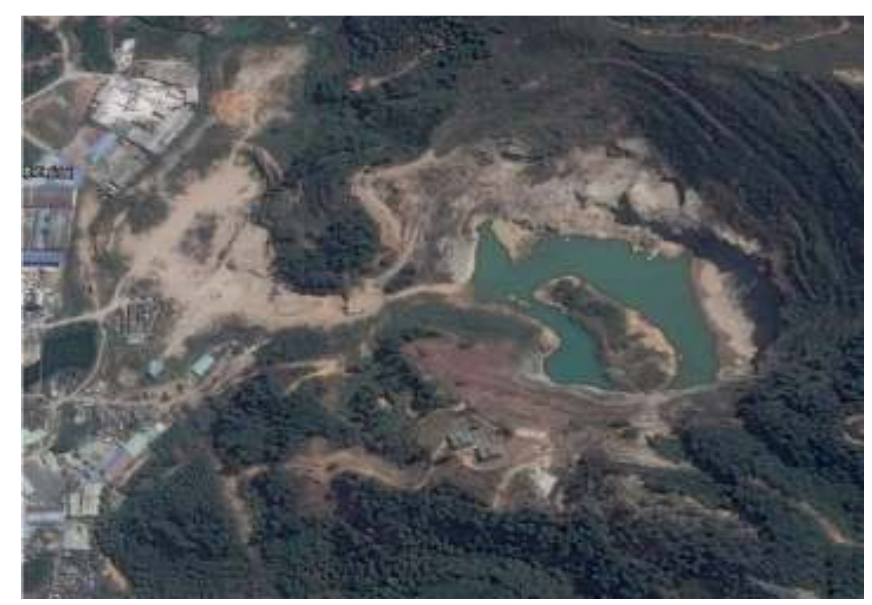

Fig. 2 Abandoned quarry prior to waste dump on the WDS site (Google earth image facing East, Nov. 2013). 
The rapid build-up of the waste pile and the amount of materials on the site had become concerns based on reports. In January 2015, an assessment from an environmental consulting firm warned that erosion at the site was "threatening the safety of hills and slopes" (Buckley and Ramzy 2015). A team of geological hazard experts reached similar initial conclusions, according to a report by the Ministry of Land and Resources (MLR 2015), that at the dumping ground for construction wastes "the accumulation was large and too steep, causing a loss of stability".

In our effort to collect information on the event, no documents on management, plan or practice of waste dumping on the site were available, nor was any onsite water drainage system. Our analysis will therefore be based on information estimated from descriptions in reports and Google earth images, with focus on the effects of slope height, slope angle and material properties of the waste pile, and the water condition anticipated onsite.

\section{Investigation of the Failure Site through Satellite Images}

Satellite images were taken using Google earth. Figure 1 is a bird view of the topography of the slide site. The waste dump site is located in a gently hilling area, approximately half way up the hill, with three sides surrounded by hill ridges and one side facing downhill. The industrial park is located near the bottom of the hill, approximately $750 \mathrm{~m}$ away and $150 \mathrm{~m}$ below the dump ground. The dump site covered an area of approximately $90,000 \mathrm{~m}^{2}, 320 \mathrm{~m}$ long and $280 \mathrm{~m}$ wide (Fig. 1).

Two vertical section views were taken by Google earth images, one section cross the sliding direction (Path 1 in Fig. 3) and another section along the sliding direction (Path 2 in Fig. 4), to show the surface topography.

The vertical section along Path 1 cuts through the central area of the dump site and near the highest point on the pile. As shown by the

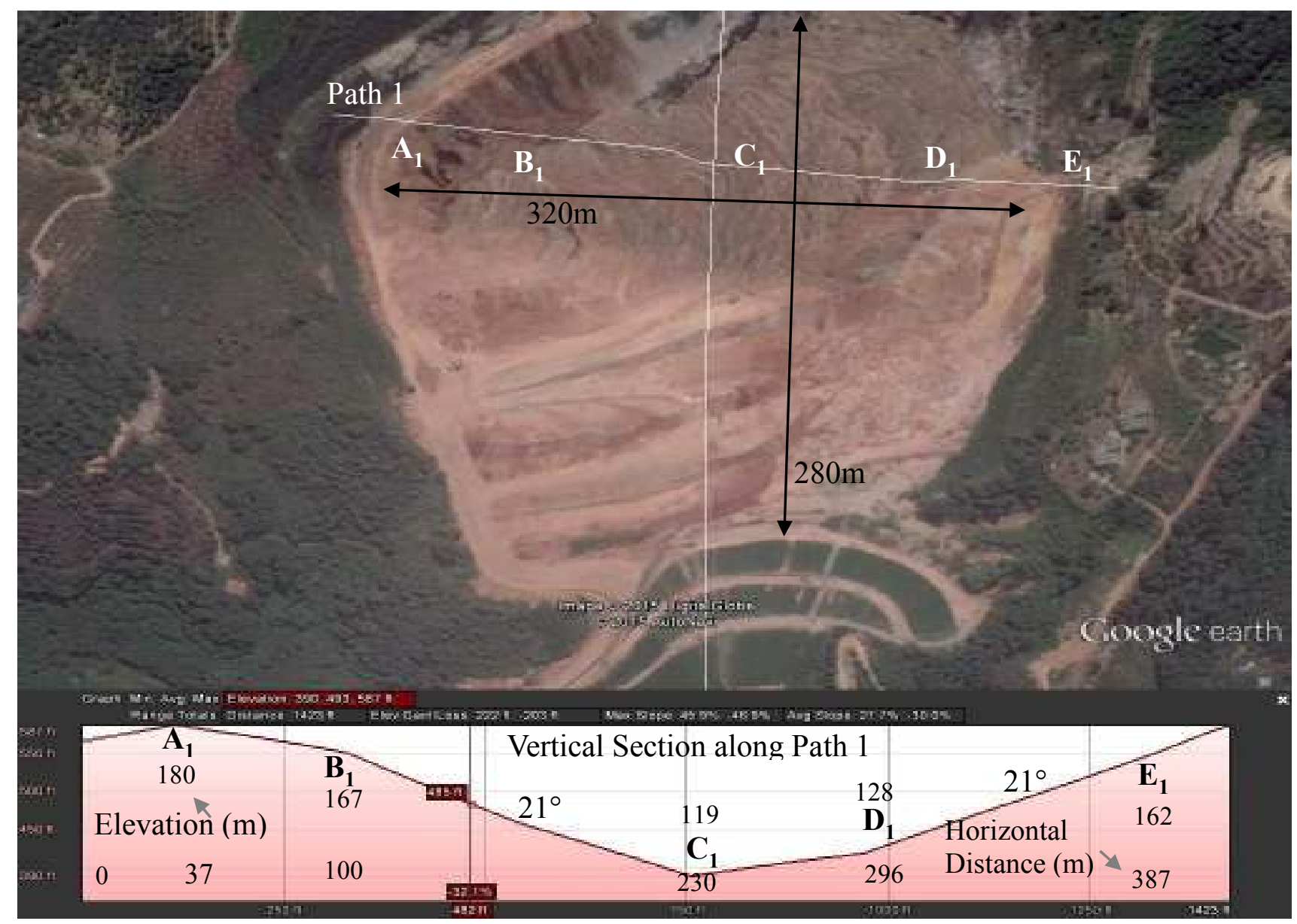

Fig. 3 Section view Path 1 (Google earth image facing South, Oct. 2015). 


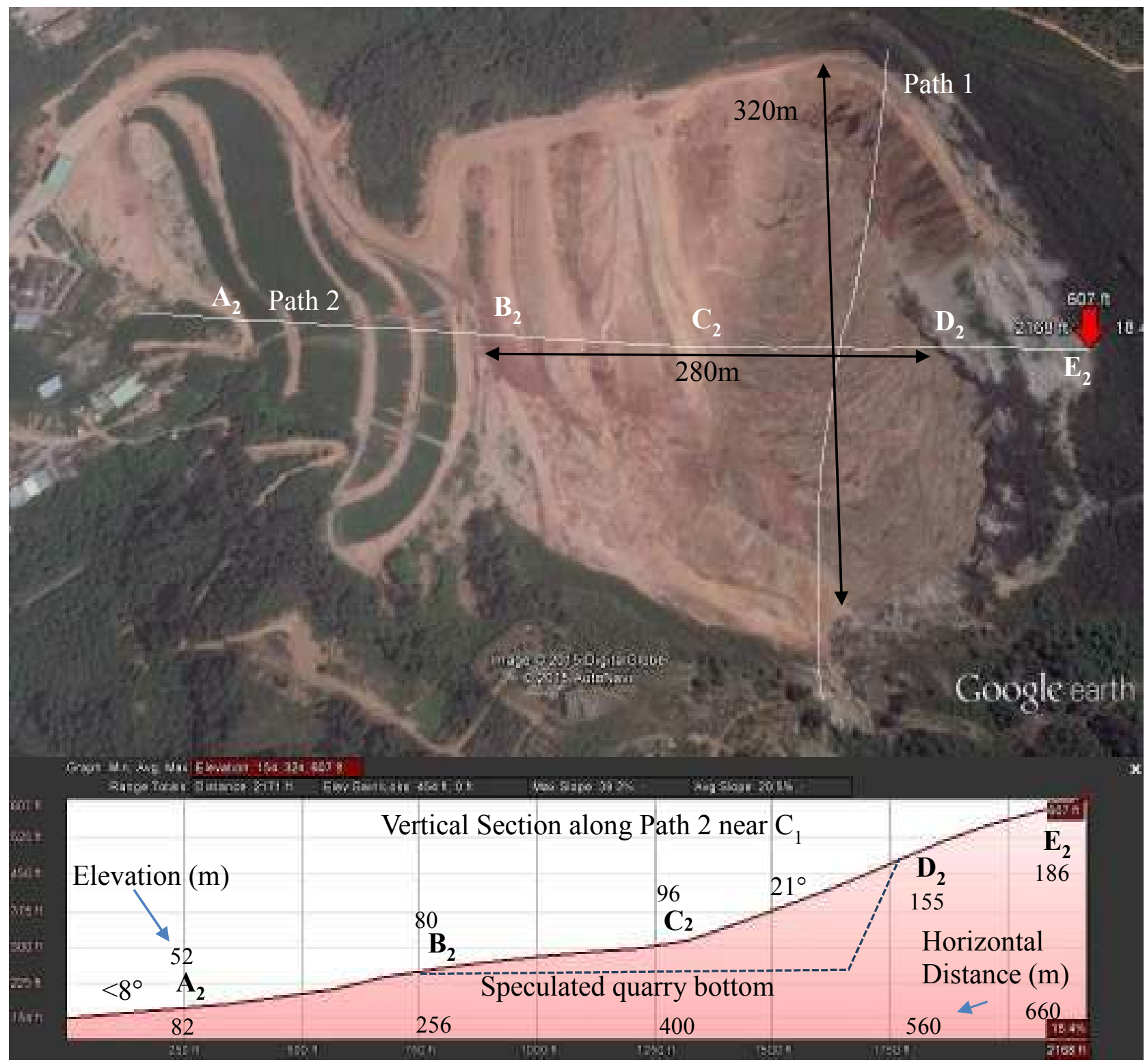

Fig. 4 Section view Path 2 (Google earth image facing East, Oct. 2015). Average slope between $\mathrm{C}_{2}$ and $\mathrm{D}_{2}$ on different sections varies between $21^{\circ} \sim 27^{\circ}$, with max slope of $45^{\circ} \sim 49^{\circ}$. Elevation at the industrial park is approximately $30 \mathrm{~m}$.

elevation in Fig. 3, the height of the dump pile is not even along Path 1 cross the pile. The central area near Point $C_{1}$ is $40 \mathrm{~m}$ lower or more than both sides. This may suggest that dumping was from both sides of the quarry during the last stage. The visible roads on both sides of the quarry would support this suggestion.

The vertical section on Path 2 is along the slide direction through the central area of the dump site, near Point $\mathrm{C}_{1}$, the lowest point on path 1 (Fig. 3). The elevation profile of the section is shown in Fig. 4, which revealed two zones: the flatter area (between $\mathrm{B}_{2}$ and $\mathrm{C}_{2}$ ) at the lower portion of the waste pile near the pit bottom, and the steeper zone (between $\mathrm{C}_{2}$ and $\mathrm{D}_{2}$ ) at the upper portion of the waste pile close to the hill side. The average overall slope angle of the waste pile is $<12^{\circ}$ in the lower portion and approximately $21^{\circ}$, in the upper portion. However, Google earth indicated much steeper slope $\left(40^{\circ} \sim 49^{\circ}\right)$ in local areas in the $C_{2}$ $\mathrm{D}_{2}$ zone on Path 2. This may be due to the uneven surface of the waste pile, or the bench slopes created during dumping. Since the WDS slide mobilized the mass of the waste pile, the overall slope stability is of our primary interest and only the overall slope angle is considered in analysis. 
Similar vertical sections, parallel to Path 2 at other locations, showed higher elevation profile and steeper overall slope (up to $27^{\circ}$ ) than those in Fig. 4. In some paths, there are no clear indication of two zones and no slope change near Point $\mathrm{C}_{2}$.

Based on the above information, it is possible to reconstruct the original quarry pit profile before any waste dumping on the site. This is shown in Fig. 4 as the dotted lines in the vertical section, with $\mathrm{D}_{2}$ as the highest point of the pit high-wall and $\mathrm{B}_{2}$ the out most point at the pit bottom. The pit bottom is not perfectly flat because water accumulated there before (Fig. 2). However for simplicity, a flat pit bottom is assumed for stability analysis. The slope angle of the high-wall in the pit is assumed to be $75^{\circ}$, which is considered reasonable for a rock quarry and is not expected to have any impact the stability of the waste pile in the pit. Our focus of analysis will be on the waste pile stability.

Google earth showed slope of the natural hill in the steeper section in a range between $30^{\circ} \sim 38^{\circ}$. An average angle of $35^{\circ}$ for the slope above Point $\mathrm{D}_{2}$ will be used in stability analysis.

\section{Analysis of the Waste Pile Stability by Numerical Modelling}

In general, the overall stability of the waste pile may be affected by a number of factors including slope angle and height of the waste pile, shear strength of the waste materials which is related to compaction onsite, water condition and erosion, and weathering-caused tension cracks on top of the pile. The stability of the waste pile is analyzed with consideration of those factors in a range anticipated in the field.

Several different profiles are suggested for the dump pile on the site. However at the time of failure, the waste pile seemed to have reached the highest point near Point $\mathrm{D}_{2}$ (Fig. 4). The height of the pile is considered full onsite and only variation of slope angle is analyzed. A waste pile profile with an overall slope angle $\psi$ at $19^{\circ}, 27^{\circ}$ and $35^{\circ}$, respectively, will be modelled for stability analysis. A typical dump pile profile is shown in Fig. 5. In this model, the primary factors in consideration are slope angle, material properties and water condition.

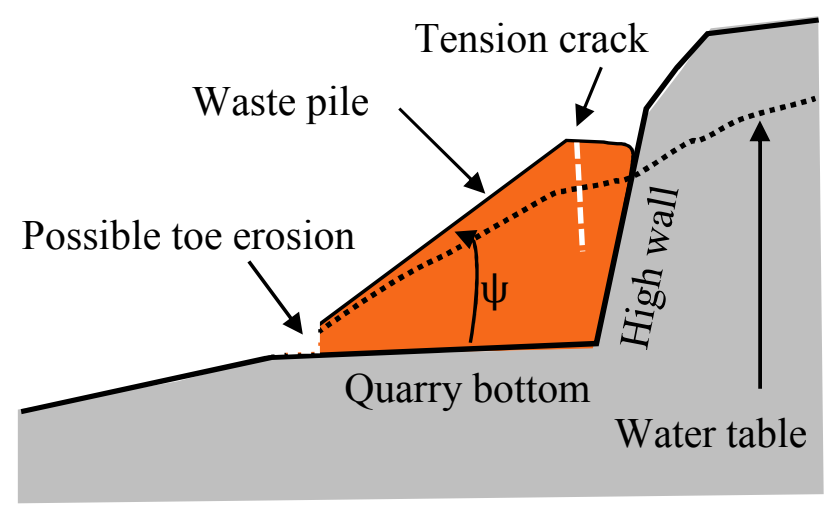

Fig. 5 Typical waste dump profile for numerical modelling

For a waste pile, the common failure mode is rotational failure. Material properties of a waste pile can be represented by two shear strength parameters $(c, \varnothing)$ in this situation. They are normally related to the degree of compaction of the waste materials onsite and will have a great influence on the pile stability. In reality, construction materials are likely dumped in place without mechanical compaction to follow up. It means that the waste pile will likely have $(\mathrm{c}, \varnothing)$ values in the lower range as anticipated for loose geo-materials. The WDS pile consisted of construction wastes and might include rocks, gravels, sands and clays, etc. Presence of clay may increase cohesion (c value) slightly. Ideally, $(\mathrm{c}, \emptyset)$ should be determined from triaxial tests of materials taken from the site and proper values estimated from a strength envelope on a shear stress-normal stress plot as demonstrated in Fig. 6.

Since no real material sample and actual strength data are available for the WDS pile, the (c, $\emptyset)$ values will be estimated based on other sources. Hoek and Bray (1981) gave an estimate of $(c, \varnothing)$ for weathered rocks in the following range: $\mathrm{c}=$ $20 \sim 80 \mathrm{kPa}$ and $\varnothing=20^{\circ} \sim 40^{\circ}$. They further provided a practical example of a colliery waste dump site, where the estimated properties were $\mathrm{c}=$ $20 \pm 20 \mathrm{kPa}$ and $\varnothing=30^{\circ} \mp 8^{\circ}$, correspondingly. The materials in the WDS pile are considered very similar to those in the colliery waste dump. With the above considerations, shear strength properties for the WDS pile in the range of $\mathrm{c}=40 \pm 20 \mathrm{kPa}$ and $\emptyset=30^{\circ} \mp 10^{\circ}$ are considered reasonable. Three cases on the strength envelope are considered for stability analysis, as shown in Fig. 6. 
Water condition on the failure site is unknown. Although reports indicated that "it was dry and there was no rain for several weeks prior to the slide", dry, partially drained and saturated condition are analyzed to evaluate the water effect.

Reports also indicated erosion problem on the dump site. This condition is modelled as "toe cut" with $5 \mathrm{~m}$ horizontal depth, as shown in Fig. 5, at the bottom of the waste pile to assess its effect. Tension crack on the slope surface is a common phenomenon and its effect is also modelled.

Different scenarios to be modelled are shown in Table 1, where relevant input parameters are also given.

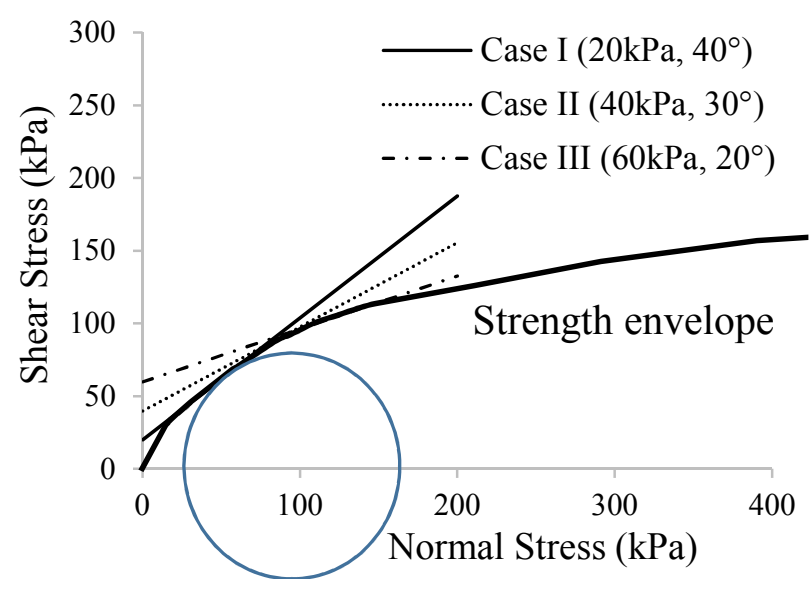

Fig. 6 Typical strength envelope from triaxial tests

Table 1 Numerical modelling scenarios and input parameters

\begin{tabular}{lcccl}
\hline \multicolumn{1}{c}{ Scenarios } & Slope $\boldsymbol{\psi}\left({ }^{\circ}\right)$ & $\begin{array}{c}\text { Waste Pile } \\
\mathbf{c}(\mathbf{k P a})\end{array}$ & $\begin{array}{c}\text { Waste Pile } \\
\boldsymbol{\emptyset}\left({ }^{\circ}\right)\end{array}$ & \multicolumn{1}{c}{ Water Condition } \\
\hline Field estimate & $21 \sim 27$ & $20 \sim 60$ & $40 \sim 20$ & Varies \\
\hline Case I & $19,27,35$ & 20 & 40 & Dry, partially drained, saturated \\
\hline Case II & $19,27,35$ & 40 & 30 & Dry, partially drained, saturated \\
\hline Case III & $19,27,35$ & 60 & 20 & Dry, partially drained, saturated \\
\hline $\begin{array}{l}\text { Toe cut and } \\
\text { Tension crack }\end{array}$ & 27 & 40 & 30 & partially drained \\
\hline
\end{tabular}

\section{Results and Discussions}

Numerical modelling was conducted using Slide from Rocscience (2015). Two types of material properties are used, one for the rock and another for the waste pile. Shear strength values of $\mathrm{c}=700$ $\mathrm{kPa}$ and $\varnothing=40^{\circ}$ are used for the rock. Material density of 17 and $25 \mathrm{kN} / \mathrm{m}^{3}$ are used for the waste pile and rock, respectively. Safety factor for the worst case based on rotational failure is calculated in each model. A typical output from modelling is shown in Fig. 7.

The results of safety factor for the three cases shown in Table 1 are plotted in Fig. 8 againt slope angle for three different water conditions. The critical condition of safety factor $=1.0$ is marked by red lines.

As shown in Fig. 8, increase of slope angle and water level would reduce the value of safety factor and therefore the stability. Based on the slope profile of the waste pile (with an agle between $21^{\circ}$ to $27^{\circ}$ ) and the water condition between dry and saturation before the slide failure, the stability of the waste pile most likely corresponded to the shaded areas above the red lines.

The actual water condition on the WDS site is unknown. It was reported as dry and no rain for a few weeks before the failure. However, the topography of the site (Fig. 1) inidcated that

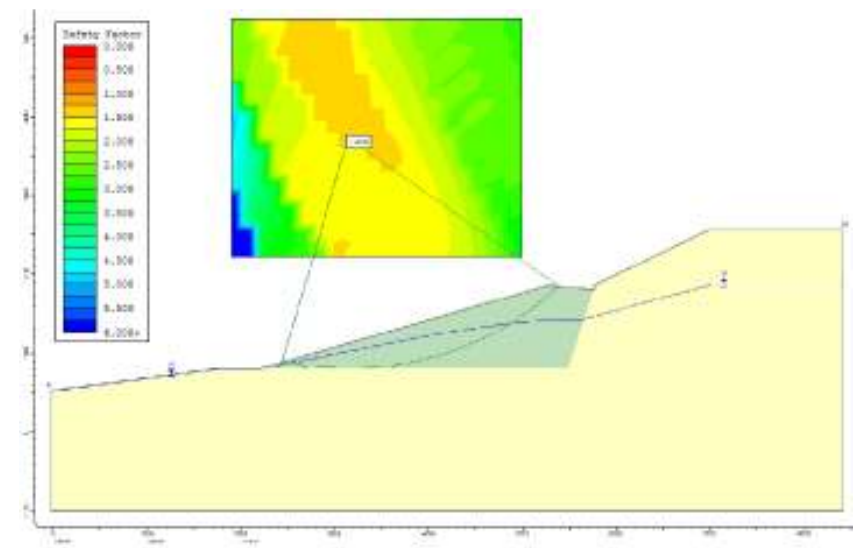

Fig. 7 Typical outcome of rotational failure analysis 

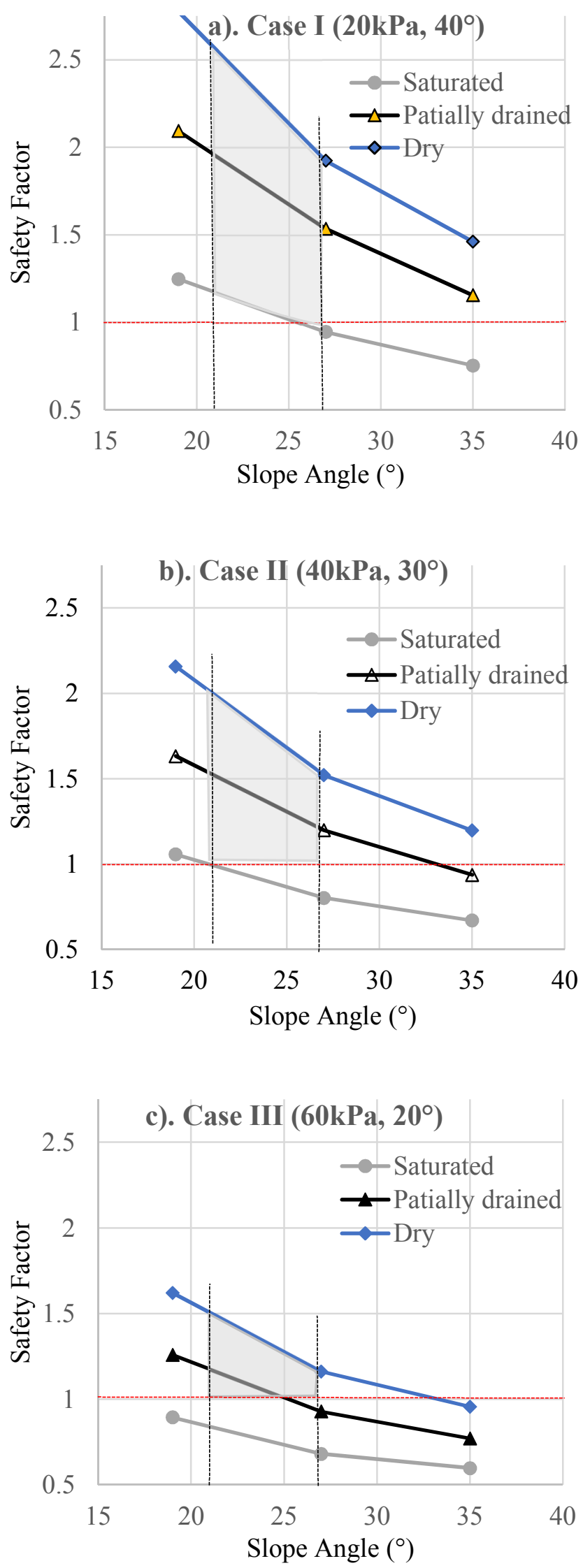

Fig. 8 Safety factor varying with slope angle and water conditions rainfall water collected in an area of 2.7 times of the size of the dump site would have flowed into the waste pile. Without the waste pile, the water would have been accumulated in a pond as shown in Fig. 2. With the waste pile in place, the water would have been absorbed in the pile whether it is visible on the surface or not. Without field measurement, it is difficult to determine the actual water table. It is however reasonable to assume a water condition on the WDS site to correspond to the partially drained condition.

It can be seen from Fig. 8 that in both Cases I and II, the safety factor is above 1.25 for the partially drained condition at slope angle $\leq 30^{\circ}$, indicating a stable pile. In Case III, the pile lost its stability at slope angle of approximately $26^{\circ}$ and higher.

The results for the partially drained conditon corresponding the stength parameters of Cases I to III are replotted in Fig. 9. It shows that the shear strength parameters for the waste pile most likely lie between Cases II and III, with estimated $\mathrm{c}=$ $40 \sim 60 \mathrm{kPa}$ and $\varnothing=30^{\circ} \sim 20^{\circ}$, Case IV being a typical representation.

Toe erosion and tension crack on the slope are also simulated as indicated in Table 1. In these modelling configurations, they both showed some but little effects on the values of the safety factor. They in general will reduce the stability and erosion should be avoided in the field. For more detailed analysis of the effects of erosion and tension cracks, more accurate field data will required from field investigations.

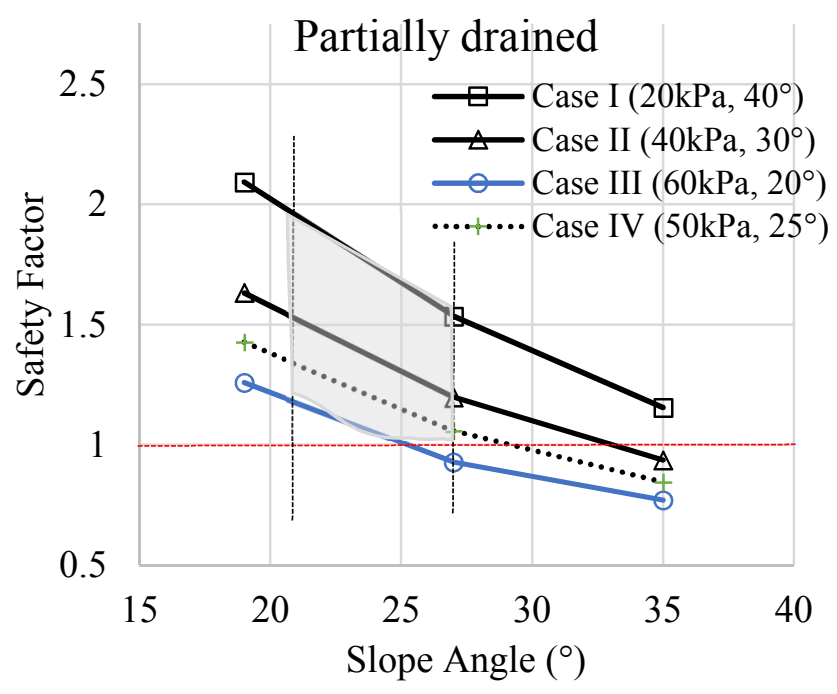

Fig. 9 Case IV as a representation of the WDS site 


\section{Possible causes for slide failure}

Based on the above results of numerical modelling, for a waste pile in a condition similar to that of the WDS slide, the most influential factors are the slope angle, the height of the pile, and the water table onsite. Slide failure may occur when any of the following conditions exists:

- The waste pile has exceeded the maximum height at a given slope angle. Under the assumed conditions, the pile height should be less than $100 \mathrm{~m}$ for an overall slope angle of $27^{\circ}$.

- The slope of the waste pile becomes too steep for a targeted height. Under the assumed conditions, the overall slope angle should be reduced to below $27^{\circ}$ if the height is $100 \mathrm{~m}$ or higher, or alternatively, the height is to be reduced while keeping the slope angle unchanged.

- The water table or water pressure in the waste pile has built up to some level. Generally, the higher the water table, the less stable for the pile. In severe conditions as would be expected during a heavy rainfall storm, which may cause liquefaction, the stability of a waste pile will be significantly reduced. It is important to point out that when a waste pile is saturated, as in a storm, slide failure become inevitable as indicated in Fig. 8 b and c).

Toe erosion and tension crack on the slope surface are progressive processes and their influence on stability will take effect gradually and slowly, but can be significant.

For the WDS slide, the real cause of slide failure can only be determined through a detailed site investigation and engineering analysis. Field investigation should provide reasonably accurate information on height, overall slope, shear strength properties of the waste pile, and water condition onsite.

\section{General Prevention Measures}

For a waste pile as considered in the analysis, slide failure can be prevented by eliminating the above conditions which are likely to cause failure. There are a few options to achieve the goal, depending on the site conditions. In general, the following measures may be taken to prevent failure:
- Conduct a thorough geotechnical investigation to determine the water and other field condition onsite.

- Conduct triaxial tests on samples taken from the site or similar condition to determine the effective shear strength parameters.

- Design the waste pile to limit its height and slope angle by a professional engineer, taking into consideration of the site conditions and material properties. Higher pile will tolerate less steep slope and vice versus.

- Design and construct surface water drainage systems onsite, particularly above and around the dump site, to prevent water from flowing into the dump site. If necessary, design and construct water drainage systems inside the waste pile to help drain the pile.

- After dumping is complete, build proper surface cover to prevent erosion and seepage of running rainfall water.

- If necessary and economically viable, methods for stabilization of the waste dump site can also be considered, which will however be site specific.

\section{Conclusions and Recommendations}

For a waste dump pile similar to the one on the WDS site, the analysis indicated that several factors may cause slide failure, including:

- the pile being too high for the overall slope angle,

- the pile being too steep for the final pile height,

- water table or water pressure inside the waste pile being too high.

The analysis also showed that the shear strength properties for loose waste materials are most likely within the following ranges: $\mathrm{c}=40 \sim 60$ $\mathrm{kPa}$ and $\varnothing=30^{\circ} \sim 20^{\circ}$, correspondingly.

However the actual failure cause of the WDS slide can only be determined with further work of field investigation and more accurate analysis.

\section{Acknowledgement}

Assistance from two graduate students in numerical modelling and data analysis is greatly appreciated. The author is grateful to his colleagues for their comments on the manuscript 
and also to Google earth for the convenience of obtaining the topography images.

\section{References}

Buckley, C. and A. Ramzy, 2015. News report. http://www.nytimes.com/2015/12/23/world/asi a/landslide-shenzhen-china.html.

Hoek, E. and J. Bray, 1981. Rock Slope Engineering. Institution of Mining and Metallurgy, $3^{\text {rd }}$ Ed., London, 358p.

Ministry of Land and Resources (MLR) News, 2015. Shenzhen slide and collapse of buildings.

http://www.mlr.gov.cn/xwdt/jrxw/201512/t201 $\underline{51221 \text { 1392254.htm. }}$.
Rocscience, 2015. Slide 6.0 - Numerical simulation software, education version. https://www.rocscience.com

Sina News, 2015. http://news.sina.com.cn/c/z/szsthp2015/.

Wangyi News, 2015. http://news.163.com/special/shenzhensthp.

Watkings, D, 2015. News report "How a hill of dirt and debris collapsed in a landslide...". http://www.nytimes.com/interactive/2015/12/2 1/world/asia/shenzhen-landslide-mapsphotos.html.

Wikipedia, 2015. 2015 News report. https://en.wikipedia.org/wiki/2015 Shenzhen landslide.

Xinhua News, 2015. http://fms.news.cn/swf/szhpsg/ 